Paidéia, 2003, 13(25), 97-109

\title{
RITUAL DE DESPEDIDA EM FAMILIARES DE PACIENTES COM PROGNÓSTICO RESERVADO ${ }^{1}$
}

\author{
Márcia Lucrecia Lisbôa ${ }^{2}$ \\ Maria Aparecida Crepaldi \\ Universidade Federal de Santa Catarina
}

\begin{abstract}
RESUMO: Pesquisa qualitativa que teve por objetivo investigar os efeitos terapêuticos do ritual de despedida na iminência da morte, em familiares de pacientes com prognóstico reservado. Foram estudadas oito famílias de pacientes internados em um Hospital Geral. Utilizou-se o método clínico, as técnicas de estudo de caso e entrevistas pós-óbito, dados submetidos à análise de conteúdo. Os resultados mostraram que os familiares se despediram através da comunicação verbal e não-verbal, da religião, da "liberaçãa", do "estar junto", sendo favoráveis à realização do ritual, pelo aprendizado, privilégio de participar e importância da orientação psicológica. São dificuldades: sentimentos de pena, tristeza, angústia e falta de coragem. Efeitos do ritual: conforto, tranquiilidade, alívio da impotência, de culpas, da tristeza, ajuda na aceitação da morte, a aproximação entre os familiares e o paciente, abertura da comunicação, melhoria de condições para elaborar o luto, redefinição dos relacionamentos com a pessoa ainda em vida.
\end{abstract}

Palavras-chave: ritual de despedida; família; morte.

\section{FAREWELL RITUAL IN RELATIVES OF PATIENTS WITH A TERMINAL DISEASE}

ABSTRACT: A qualitative research about the therapeutic effects of the farewell ritual at the imminence of death, in relatives of patients with a terminal disease. Eight families of patients hospitalized at a General Hospital were studied. It was used clinical method, case study technique and interviews after the patient's death, with the data analyzed through the Content Analysis method. The results show that the relatives presented their farewell through verbal and non-verbal communication, religion, "liberation", "being together", and they were favorable to the ritual realization, highlighting the learning, the privilege in participating and the psychology guidance importance. As difficulties, they reported the feelings of pity, sadness, anguish and the lack of courage. The rituals effects were: comfort, tranquility; relief of impotence and sadness, death acceptance help, relatives and patient closeness, the communication openness between them, conditions improvement to deal with mourning, relationships redefinition with the person still alive.

Key words: farewell ritual; family, death

A morte é um momento geralmente difícil de ser enfrentado, tanto para a pessoa que está morrendo, quanto para seus familiares. Dependendo do nível de aceitação da morte, do padrão de relacionamento existente entre a pessoa que está morrendo e sua família, do seu papel na mesma, das crenças so-

\footnotetext{
' Artigo recebido para publicação em 26/11/02; aceito em 06/02/03

2 Endereço para correspondência: Márcia Lucrecia Lisboa, Av. Max de Souza, 1545, Apto. 402, Coqueiros, Florianópolis, SC, Cep 88080000, E-mail: marciallisboa@hotmail.com
}

bre a morte e do tipo de morte (se é súbita ou prolongada), o seu enfrentamento pode se dar de maneiras diferentes.

No caso de pessoas com doenças crônicas em estágio avançado, por se tratar de uma morte prolongada, existe um tempo maior de preparação para a mesma. Porém, muitas vezes o paciente e/ou seus familiares têm dificuldades em aceitar e enfrentar a morte. Um dos fatores que pode dificultar esta aceitação é o tipo de vínculo afetivo existente entre a 


\section{Márcia Lucrecia Lisbôa}

pessoa que está morrendo e os familiares. Observase, na prática, que o sofrimento das pessoas envolvidas em "romper" este vínculo é tão forte que parecem desejar um adiamento do momento da morte, $e$ quando esta ocorre, observa-se que enfrentam a mesma com muita dor e sofrimento. Considerando estes aspectos, a intervenção psicológica tem se viabilizado como uma possibilidade de minimização deste sofrimento, atuando no sentido de orientar e estimular os familiares e o paciente a lidarem com a situação, conversando sobre temáticas tais como despedidas, agradecimentos e pedidos de perdão que julgarem necessários, possibilitando assim a redefinição de questões que possam estar pendentes no relacionamento familiar.

Entende-se por redefinição a mudança no modo de ver uma situação ou de se relacionar (Andolfi, 1996; Groisman, 1991; Whitaker \& Bumberry, 1990). Questões pendentes referem-se a temas e assuntos que são interditos, relações que estão truncadas, fechadas ou não resolvidas, que afetam o relacionamento entre o familiar e a pessoa que está morrendo. Por aceitação entende-se admitir a perda, pois não se pode dizer que ocorra uma aceitação genuína da morte tendo em vista o interdito da mesma em nossa sociedade contemporânea ocidental. Pressupõe-se, portanto, que ao admitir a perda do ente querido, o familiar apresente uma elaboração, ainda que relati$\mathrm{va}$, dos sentimentos de raiva, revolta, angústia ou depressão relacionados à morte iminente, e/ou à morte propriamente dita, podendo assim encontrar estratégias de enfrentamento que sejam mais harmônicas.

O processo de despedida dos familiares e pacientes em iminência de morte é chamado, neste artigo, de ritual de despedida. A literatura pesquisada não define o que seja ritual de despedida. Imber-Black (1998) fala em rituais de luto, rituais funerários, rituais de elaboração, rituais terapêuticos. Porém, parece estar se referindo aos rituais após a morte concreta. Cita a importância de rituais de carinho diante da proximidade da morte e da perda de pessoas que morrem em hospitais. Bowen (1998), Walsh e McGoldrick (1998) falam de rituais funerários; Scheff (1979) cita rituais de luto. Todos parecem estar se referindo aos momentos posteriores à morte. Friedman (1995) salienta a importância de se envolver e intervir numa família nos momentos anteriores e posterio- res aos rituais, chamando-os de ritos de passagem. Baseando-se então nestas definições, pode-se ter indícios de que o termo ritual de despedida é adequado à situação.

Segundo Kovács (1991), até o início da década passada existiam poucos artigos e pesquis as publicadas referentes ao trabalho de psicólogos com pessoas diante da morte. Salienta que o tema da morte é um campo de estudos fértil para a Psicologia como reflexão, ciência e prática e, sendo o psicólogo também um profissional de Saúde, tem também a morte no seu cotidiano profissional.(1989).

Kellehear e Lewin também escrevem que as despedidas do morrer têm recebido pouca atenção das Ciências Sociais, tendo existido até o final da década de 80 poucos trabalhos que exploraram esta questão. Porém, até os dias de hoje, ainda há pouquíssimos trabalhos específicos $e$ empíricos que abordem o tema das despedidas do morrer.

A teoria e prática da terapia familiar em suas diferentes abordagens também negligenciou, até há pouco tempo, as questões referentes à morte. $\mathrm{O}$ paciente pertence a um grupo social que é a família; conseqüentemente, esta também sofre o impacto da terminalidade e busca formas de apoio nesse enfrentamento. A morte cumpre uma etapa do desenvolvimento do ciclo vital da família e, por esta razão, não pode ser negligenciada.

Como destaca Becker (citado por Rolland, 1998), a maior parte dos estudos feitos na área de luto e família, até há pouco tempo, abordavam questões voltadas ao pós-morte, ou seja, à elaboração ou não do luto após a morte concreta de um membro da família. Justifica este fato colocando que abordar questões referentes à perda futura implica em tomar contato com sua própria mortalidade, sendo uma forma de antecipar os sentimentos inerentes a esta constatação, o que pode acionar a negação da mesma.

A prática atual dos profissionais que atuam junto a pessoas enlutadas mostra a necessidade de oferecer cuidados às mesmas, como medida de prevenção em saúde mental. A perda e o luto afetam as pessoas, causando sintomas emocionais, como a depressão e a ansiedade, assim como sintomas físicos. Por isso, a importância que pode ter na prevenção 
destes sintomas a oferta de apoio e o encorajamento aos familiares para que expressem seus sentimentos

São várias as consequiências para um membro da família com dificuldades em viver e elaborar o luto pela morte de um ente querido. Muitos dos sintomas que chegam aos consultórios médicos e psicológicos podem ser oriundos de um luto não resolvido. Franklin (1997) afirma que as pessoas que reprimem seus sentimentos de luto, ou que têm tendência à depressão e à ansiedade, podem desenvolver reações agudas em estágios posteriores da vida, devido ao luto não resolvido. Destaca que as pessoas enlutadas procuram mais constantemente atendimento médico no primeiro ano seguido à morte de um familiar, pois o sistema imunológico é afetado pelo luto. Desta maneira, após um longo período de atendimento a um ente querido próximo da morte, a saúde do enlutado sofre, pois sua rotina de vida e de dormir são alteradas.

A partir deste tema, as autoras do presente artigo realizaram uma pesquisa, cujo objetivo foi investigar mais amplamente quais os efeitos terapêuticos do ritual de despedida na iminência da morte, em familiares de pacientes com doenças em estágio avançado. Por efeito terapêutico entende-se a probabilidade das pessoas de tomarem contato com a possibilidade de morte, ou da morte propriamente dita de uma pessoa muito próxima, como um parente ou amigo, enfrentando este fato e aprendendo a lidar com o mesmo, de forma a permitir a elaboração do luto, para assim encarar o cotidiano de forma saudável para o seu desenvolvimento ulterior.

Para a realização desta pesquisa, partiu-se da hipótese de que o ritual de despedida na iminência da morte auxilia as famílias no enfrentamento da mesma e na elaboração do luto, prevenindo o desenvolvimento de sintomas psicológicos. Pode também reaproximar a família do seu ente que está morrendo e diminuir a sensação de impotência dos familiares diante da morte. Com o crescente aumento do interesse pela área de Psicologia Hospitalar e da Saúde, e também pelo tema da morte em outras disciplinas, tais como Medicina, Enfermagem, Serviço Social, Sociologia, Antropologia, entre outras, esta pesquisa poderá trazer subsídios que possam esclarecer e orientar profissionais que atuam junto a pacientes com prognóstico reservado e seus familiares, no sentido de minimizar o sofrimento dos mesmos.

A morte é um fato universal, porém seu enfrentamento e significado variam de sociedade para sociedade. A realidade brasileira mostra que, cada vez mais, morre-se nos hospitais, sendo essencial que os profissionais da saúde, dentre eles o psicólogo, possam estar preparados para ajudar as famílias neste momento tão significativo da vida.

\section{Método}

Utilizou-se o método clínico, e trata-se de uma pesquisa qualitativa. A população pesquisada foi composta por familiares de pacientes portadores de doenças crônicas em estágio avançado, internados nas enfermarias de Clínica Médica do Hospital Universitário da Universidade Federal de Santa Catarina, em Florianópolis, que participaram mediante consentimento livre e informado. Foram acompanhadas oito familias e doze familiares, cujas idades variaram entre 28 e 74 anos, de ambos os sexos, com graus variados de parentesco com o paciente e de diversas religiões. Alguns naturais da Grande Florianópolis ou ainda de outras regiões do Estado, do país e da América do Sul.

A coleta de dados foi realizada em duas etapas. A primeira etapa teve como objetivo principal coletar os dados referentes ao acompanhamento do familiar em processo de despedida do seu parente que estava à morte, para posterior descrição detalhada do processo de despedida, incluindo o ritual. Para tanto, utilizamos a técnica de estudo de caso, ou seja, a coleta de dados foi feita no momento mesmo da intervenção psicológica, a partir dos atendimentos realizados por uma das autoras.

Os atendimentos deram-se da seguinte maneira: 1) partiu-se da solicitação de atendimento por algum profissional da equipe de saúde, pelo familiar, ou através da verificação pela própria psicóloga, no Livro de Ocorrências da Enfermaria, se havia algum paciente com prognóstico reservado que estivesse acompanhado por algum familiar; 2) procurou-se $o$ paciente e/ou o(s) familiar(es), geralmente junto ao leito daquele, apresentou-se o Serviço e verificou-se a disponibilidade deles para atendimento psicológico. Quando o encaminhamento havia partido da equipe, 


\section{Márcia Lucrecia Lisbôa}

isso era comunicado ao paciente e/ou à família, bem como o motivo do mesmo. Muitas vezes, o paciente se encontrava sonolento, desorientado ou comatoso, sendo que a abordagem foi feita apenas com o(s) familiar(es); 3) havendo disponibilidade e confirmando-se a necessidade de acompanhamento, realizouse entrevistas clínicas para verificar as expectativas dos familiares e, quando possível, do paciente, com relação à evolução da doença, seus conhecimentos do diagnóstico e prognóstico, seus níveis de aceitação da morte iminente, quais as características das relações entre os familiares e o paciente, se existiam questões não resolvidas no relacionamento e quais as pessoas com quem o paciente tinha um vínculo mais significativo; 4) discutiu-se, então, as possíveis dificuldades que eles apresentavam com relação ao enfrentamento da morte, ouvindo-os e pontuando aspectos relevantes; 5) quando a avaliação indicava haver uma aceitação suficiente da morte, mesmo que não fosse total (pois poderia haver sentimentos de raiva, esperança, dor, medo da separação, concomitantes), orientou-se os familiares com relação às despedidas e à importância de comunicarem ao paciente agradecimentos, pedidos de perdão, e também que respeitariam a escolha deste em continuar lutando pela vida, ou aceitar a possibilidade de morte. Orientou-se também que, na medida do possível, as pessoas cujo vínculo fosse muito significativo com o paciente comparecessem ao hospital e realizassem este ritual. Durante a realização do mesmo, a psicóloga permaneceu, quando possível, junto a eles, dando apoio e intervindo se e quando necessário.

Ressalta-se que o número de atendimentos, o tempo de acompanhamento e o número de familiares ao qual se teve acesso, foi variável e não previsível. Todos os atendimentos feitos à família foram registrados a posteriori, de forma manual e cursiva.

A segunda etapa da coleta de dados foi realizada fazendo-se uma entrevista pós-6bito com os familiares, entre 1 e 2 meses após a morte do paciente, para avaliação do ritual de despedida. As entrevistas tiveram dois blocos: a avaliação do ritual de despedida e as condições de vida, em geral, do entrevistado após a morte do familiar. Foram entrevistados familiares que acompanharam o paciente no hospital e que passaram pelo processo do ritual de despedida. Algumas entrevistas pós-óbito foram individuais, outras foram em conjunto com mais de um membro da mesma família, sendo gravadas em áudio e transcritas literalmente.

Para proceder à análise dos dados, utilizou-se a metodologia de Análise de Conteúdo (Bardin, 1984; Crepaldi, 1989), ou seja, o material coletado foi organizado conjuntamente, ressaltando-se os componentes dos discursos, palavras e mensagens, associando-os com temas diversos. Na Análise Temática, primeiramente realizou-se a pré-análise, quando foram escolhidos os documentos a serem analisados. A partir disso, fez-se uma leitura flutuante e exaustiva do conjunto de comunicações (entrevistas clínicas e entrevistas pós-óbito) e constituiu-se o corpus, organizando-se o material e determinado as unidades de significado, ou seja, as frases significativas com relação ao contexto da pesquisa. Após esta primeira etapa, fez-se o tratamento de descrição dos resultados obtidos e a interpretação, quando os resultados foram descritos e analisados com o objetivo de uma compreensão aprofundada dos conteúdos manifestos e latentes.

A pesquisa abrangeu uma análise clínica do material coletado, segundo a abordagem sistêmica em Psicologia (Andolfi, 1996; Bromberg, 1997, 1998; Calil, 1987; Walsh \& McGoldrick, 1998) que entende a família como um sistema em interação permanente, que se autogoverna através de regras e, quando se encontra sob a influência de determinados eventos, tais como nascimento, casamento, perda por morte ou separação, entrada dos filhos na adolescência, entre outros, vê-se diante da necessidade de reorganização para atingir um novo equilíbrio que garanta a sua sobrevivência.

\section{Resultados}

\section{Pré-requisitos}

Constatou-se que, como pré-requisitos para a realização do ritual de despedida, os familiares necessitam estar conscientes da possibilidade da morte iminente e aceitando a mesma, e que já estejam vivenciando o luto antecipatório. Portanto, os efeitos desses fatores devem ser avaliados antes da orientação e realização do ritual, ou seja, é importante avaliar como e se os familiares estão desenvolvendo o 


\section{Ritual de Despedida em Familiares 101}

luto antecipatório e qual seu nível de aceitação da morte iminente, para poder orientá-los quanto ao ritual de despedida.

Algumas questões descritas sobre o luto antecipatório (Franklin, 1997; Jann, 1998,1999; Torres, 2001; Worden, 1997) como as reações defensivas ou a negação da ameaça de perda, a natureza do vínculo entre o paciente e os familiares, os conflitos familiares, os efeitos do papel de cuidador sobre o familiar enlutado, e o fator tempo de doença, influenciam na preparação para a morte e, conseqüentemente, na realização do ritual de despedida, o que reforça a suposição de que os familiares necessitam vivenciar e elaborar o luto antecipado para poder se despedir do paciente.

Nos casos pesquisados, percebeu-se que ocorreu a aceitação da morte, e que esta foi facilitada por vários fatores, tais como: o fato de se tratarem de mortes prolongadas (Brown, 1995) em que a doença já estava num estágio terminal; a idade dos pacientes, pois a maioria já era idosa (Brown, 1995); a boa qualidade anterior da relação (Bromberg, 1998; Brown, 1995); o fato dos familiares terem estado presentes durante as fases do adoecimento (Bromberg, 1998); o stress dos cuidadores (Rolland, 1995); o sentimento de impotência diante do sofrimento (Brown, 1995); as opiniōes e crenças sobre a morte, incluindo as crenças religiosas; a aceitação do próprio paciente; a noção de boa morte (Bromberg, 1998), ou seja, aquela que é tranquiila, natural, sem prolongar o processo de morrer, sem dor e rodeado pela família; o manejo da equipe de saúde.

\section{O ritual de despedida}

O modo como os familiares se despediram de seus entes queridos foi bastante abrangente e variado. $\mathrm{O}$ como se despediram baseou-se, principalmente, na qualidade da relação anterior e no grau de consciência do paciente. A comunicação oral predominou, incluindo pedidos de perdão e agradecimentos, $\mathrm{e}$ também o desejo de tranqüilizar seu parente sobre $o$ bem-estar da família após sua morte.

Apareceu com destaque a importância dos gestos e atitudes como um fator crucial na despedida. Mesmo quando o familiar utilizou palavras para se despedir, percebeu-se que os gestos tiveram uma importância fundamental, pois reforçou o que foi dito. Nos casos onde a pessoa não conseguiu se expressar oralmente, os gestos foram suficientes para a despedida, e uma forma de demonstrar carinho e gratidão. A comunicação não-verbal foi essencial para os familiares expressarem seus sentimentos, num momento em que, muitas vezes, as palavras podem não ser suficientes ou possíveis de serem ditas.

A religião, através de leituras bíblicas, orações e extrema-unção, também permeou o modo como os familiares se despediram. Pode-se notar que, assim como na aceitação e no enfrentamento da morte, na realização do ritual a religião também tem um papel muito importante. Cada vez mais se faz necessário considerar este aspecto nas intervenções em situações de morte, pois a religião, em geral, atua como um consolo e um apoio essencial nos momentos de dor. Também no caso do ritual de despedida na iminência da morte, é fundamental compreender, respeitar e considerar as crenças e rituais religiosos como um meio dos familiares se despedirem e aliviarem seu sofrimento.

Em alguns casos, apareceu a necessidade de, aparentemente, "liberar" ou "autorizar" o paciente para "se desprender", "partir",algumas vezes também através de orações, quando os familiares pediam pela cessação do sofrimento do paciente. Apesar da literatura a que se teve acesso não abranger esta questão, é impossível ignorar os depoimentos dos familiares, que colocaram claramente a necessidade de "autorizar" a partida de seu ente querido. Muitos relatos mostraram que esta "liberação" é muito significativa nos momentos de despedida na iminência da morte, e faz parte do ritual de despedida. É como se o paciente "aguardasse uma autorização" das pessoas com quem tem um vínculo importante, para poder morrer em paz. O paciente parece sentir, desta forma, que seus familiares também não estão mais suportando o sofrimento, e estão preparados para a morte dele.

Observou-se que estar junto, acompanhar e cuidar do paciente até o momento da morte, é uma questão fundamental e uma maneira dos familiares se despedirem aos poucos do seu parente. Segundo os entrevistados, estar próximo, acompanhando a evolução da doença já há algum tempo, facilita a realização do ritual, pois aproxima ainda mais o fami- 


\section{Márcia Lucrecia Lisbôa}

liar do seu parente e auxilia na aceitação da morte. Este gesto pode ser suficiente para se despedir. Por isso, pode-se caracterizar o "estar junto", o acompanhar e cuidar do familiar doente, como uma forma de se despedir, pois parece ser uma maneira de ir "fechando" a relação; de se despedir aos poucos e de diminuir a sensação de impotência. Estar junto parece trazer felicidade, trazer a sensação de afiliação e de "missão cumprida" por ter atendido bem seu parente, trazer conforto e a idéia de ter compartilhado com o doente um momento de difícil enfrentamento. Lebow (1976) refere-se aos comportamentos de permanecer junto com o paciente e separar-se dele, em preparação para deixá-lo ir, como tarefas de adaptação para a família da pessoa que está morrendo.

Nos relatos dos familiares, observou-se que trazer outras pessoas para se despedirem é outro fator bastante relevante, e pareceu aliviar os familiares, inclusive, de sentimentos de culpa. Também apareceu a importância de pedir perdão por outros parentes que estavam ausentes. Portanto, na impossibilidade de outros familiares se despedirem pessoalmente do paciente, pode-se cogitar a possibilidade dos parentes que já estão acompanhando o familiar, ou têm disponibilidade para visitá-lo no hospital, fazerem o seu ritual incluindo as despedidas dos demais.

Nos casos em que o paciente se encontrava ainda lúcido no momento da despedida, pode-se observar, no seu ritual, aspectos semelhantes aos observados nos relatos dos familiares, além de pedidos dos pacientes quanto ao ritual funerário. Pode-se observar que aspectos que mostram os ritos relativos à morte, caracterizada por Ariès (1977) como morte domada ou morte familiar, presentes no século XV e no século XX até a Revolução Industrial, aparecem também hoje em alguns casos em que o paciente se encontra lúcido, mesmo que a morte ocorra no hospital, onde costumeiramente considera-se que a mesma seja impessoal e desacompanhada. Apareceu a importância da presença dos parentes, e da pessoa que está morrendo participar do processo de finalização de sua vida, dar as recomendações finais, manifestar suas últimas vontades, fazer pedidos de perdão e se despedir, sendo o paciente responsável pelos seus últimos momentos.

Observou-se também que o modo dos pacientes se despedirem se assemelhou ao modo dos fami- liares. O ritual dos pacientes também se baseou em comunicações verbais e não-verbais, em pedidos de perdão e agradecimentos, na necessidade de saber sobre o bem-estar dos que ficariam, e na necessidade de se sentir acompanhado pela família. $O$ que se destacou, comparando-se com o ritual dos familiares, foram os pedidos relativos à pós-morte, como por exemplo, o funeral. Barrêtto (1992), Bromberg (1998) e Kübler-Ross (1996), constataram a necessidade do paciente, frente à morte, de saldar seus débitos com as pessoas que são significativas para ele, providenciar cuidados para os que ficam e despedir-se, sendo que os pacientes referem preocupações com o futuro, com o cuidado dos filhos e com questões não resolvidas. Brown (1995) destacou a importância de discutir como o próprio paciente planeja seu funeral e enterro.

Kellehear e Lewin (1989) constataram a importância que o paciente dá às despedidas no seu leito de morte, na iminência da mesma, através da conversação, das trocas de olhares e de gestos, entre outros. Kovács (1991) escreveu sobre o sofrimento secundário dos pacientes, quando uma de suas maiores dificuldades é o medo do que pode acontecer com os dependentes, sendo que a comunicação entre o paciente e os familiares pode se dar também através do afagar das mãos, do tocar e do olhar.

\section{Opiniões sobre o ritual}

Todos os familiares entrevistados se manifestaram favoráveis à orientação e realização do ritual de despedida, colocando a sua importância, destacando a diminuição da sensação de impotência e culpa, a oportunidade de aprendizado, o privilégio de participar de um momento especial e bonito. Destacaram também se tratar de um momento com muito afeto, independentemente do estado de consciência do paciente, e a importância dos gestos, além das palavras. Os familiares entrevistados colocaram, ainda, a importância de fazer a despedida quando o paciente ainda está vivo, referindo-se à necessidade de ser perdoado por ele. Referiram-se ao ritual como fundamental para prosseguir suas vidas.

O ritual de despedida na iminência da morte parece ter os aspectos de solenidade, de sagrado e homenagem colocados por Imber-Black (1991), 
Moore e Myerhoff (1977) e Reeves e Boersma (1990), marcando o momento como sendo muito especial. O sentimento de privilégio por participar de um momento como este parece ser marcante. Também é uma oportunidade de estar mais próximo de seu familiar que está morrendo. Proporciona, ainda, crescimento, estabilidade e estrutura à pessoa, e um senso positivo de força pessoal.

\section{$A$ intervenção psicológica}

Os efeitos da orientação psicológica para a realização do ritual de despedida apareceu como um fator bastante relevante com relação ao melhor enfrentamento da morte. Pode-se perceber que o atendimento psicológico aos familiares na iminência da morte de um parente, e a orientação para a realização do ritual de despedida, é muito importante. Ter a oportunidade de trabalhar sentimentos, muitas vezes ambivalentes e "negativos", parece auxiliar bastante no enfrentamento da morte e nas despedidas, pois facilita a abertura do relacionamento e a comunicação franca entre o paciente e os familiares (Brown, 1995; Worden, 1997). O atendimento psicológico pode ajudar o familiar a lidar com questões não resolvidas com a pessoa morta ou que está morrendo, ajudá-lo a identificar e expressar sentimentos como raiva, cul$\mathrm{pa}$, ansiedade, impotência, tristeza, e estimulá-lo a dizer um adeus apropriado. Os familiares também destacaram a importância das orientações para o ritual, principalmente sobre agradecimentos, e a sugestão de trazer outros familiares para se despedirem. Num momento em que a família está envolvida em sentimentos tão fortes e confusos, é crucial ter um profissional que a oriente e lembre destas questões, ao mesmo tempo em que dá o apoio emocional necessário para fortalecer os familiares, num momento que mobiliza tantos sentimentos.

\section{Dificuldades}

Com relação às dificuldades para a realização do ritual, enfrentadas pelas famílias entrevistadas, destacaram-se os sentimentos de pena, tristeza, pesar, angústia e falta de coragem, que muitas vezes os impediram ou dificultaram no sentido de se expressa- rem oralmente. Nestes casos, a importância de poder incluir gestos e atitudes parece ser fundamental. A emoção, segundo os relatos dos entrevistados, pode ser um impedimento ou uma dificuldade no momento de se despedirem dos pacientes. Os sentimentos inerentes ao processo de luto antecipatório também podem dificultar a expressão dos mesmos, mas parecem não impedir a realização do ritual de despedida. As emoções podem impedir ou dificultar a expressão oral, bem como o raciocínio dos familiares diante da iminência da morte. Há muitos sentimentos mobilizados nestes momentos, por isso deve-se respeitar os limites de cada pessoa, oferecer um espaço para que ela possa extravasar e reorganizar suas emoções, e colocar a possibilidade de expressar o que está sentindo de várias maneiras.

\section{$O$ relacionamento anterior familiar-paciente}

Percebeu-se, também, que a qualidade anterior do relacionamento entre os familiares e o paciente influenciou na realização do ritual de despedida. Por isso, parece ser crucial estar atento à qualidade da relação entre a família e o paciente, para se avaliar a possibilidade de orientá-los com relação ao ritual de despedida, ajudando-os a identificar e compreender suas emoções, facilitando o manejo das mesmas. Se a relação anterior é comprometida, é mais difícil a pessoa conseguir cuidar do familiar que está morrendo, aproximar-se e despedir-se dele. A dificuldade maior para a realização do ritual estabelece-se quando há distância emocional entre eles e estão presentes sentimentos de raiva, culpa e orgulho, sendo que a orientação para o ritual deve ser precedida de um atendimento psicológico com o objetivo de aliviar esses sentimentos e tentar redefini-los. Neste caso o ritual de despedida pode ser muito eficaz.

Não ter questões pendentes pode facilitar a realização do ritual, pois faz com que o mesmo aconteça de forma mais tranqüila. Quando não há questões mal resolvidas e motivos para pedidos de perdão, o ritual pode ser mais orientado para agradecimentos, para tranqüilizar o paciente sobre o bem-estar dos familiares após a sua morte, para "liberá-lo" a partir, e para permanecer junto ao paciente, acompanhando-o e auxiliando nos cuidados.

No ritual de despedida, avalia-se qual (is) pes- 


\section{Márcia Lucrecia Lisbôa}

soa (s) é (são) significativa (s) parà o paciente. No caso da morte iminente, o ritual de despedida pode atuar no sentimento de pertenência (segundo ImberBlack, 1991), ou seja, quem é membro e quem não é membro do sistema familiar, pois pode aproximar ou resignificar relações anteriormente comprometidas, ou reafirmar relações já próximas. $O$ ritual de despedida pode auxiliar os pacientes $e$ suas famílias a se reaproximarem e reatarem relações antes da morte, numa tentativa de restaurar as relações prejudicadas e reconstruir a confiança mútua.

Autores como Bromberg (1997), Brown (1995), Kovács (1991), Friedman (1995), Simonton (1990) e Worden (1997) afirmam a importância de se considerar e avaliar a qualidade do relacionamento entre o paciente que está morrendo e seus familiares, pois a maneira como cada um dos membros da família irá lidar com sentimentos de ambivalência, culpa e vergonha depende da relação estabelecida entre eles, e o familiar que reagirá mais à morte iminente será aquele que estabilizou sua vida através de algum tipo de dependência emocional em relação à pessoa que está morrendo. Por isso, deve-se intervir quando necessário, no sentido de tentar redefinir relacionamentos comprometidos, auxiliando-os no enfrentamento da perda e nas despedidas, pois os ritos de passagem numa familia podem ser uma oportunidade para mudanças nos seus padrões de relacionamento.

\section{O grau de consciência do paciente}

O fato do paciente estar consciente, sonolento ou comatoso influencia no modo como o familiar fará a despedida. Por um lado, se o paciente está consciente, pode-se redefinir mais amplamente relações pendentes, sendo uma despedida bilateral. Porém, o estado de vigília também pode constranger o familiar a fazer pedidos de perdão e agradecimentos, principalmente se o paciente não manifesta abertamente estar ciente de sua morte iminente e/ou se a comunicação intra-familiar está fechada. Nos casos pesquisados, o fato do paciente estar comatoso parece não ter influenciado negativamente na despedida, pois a maioria dos familiares referiram acreditar que o seu familiar que estava morrendo "ouvia" o que estava sendo dito ou "sentia" a presença da família ao seu redor. Isto parece ter facilitado no momento do ritual de despedida.

\section{Efeitos do ritual}

Os familiares destacaram o conforto e a tranqüilidade que o ritual proporcionou, $o$ alívio de culpas e da tristeza, a ajuda na aceitação da morte e na recuperação da família, e a aproximação entre os familiares e o paciente. $O$ ritual de despedida na iminência da morte parece ter efeitos análogos aos que os autores chamam de rituais de luto, pois parece reduzir os efeitos debilitantes da tristeza (Friedman, 1995), aproximar a família da pessoa que está morrendo, resolver crises de vida, melhorar o funcionamento emocional da família, dissolver sentimentos de culpa e remorso, e prestar uma última homenagem ao familiar que está morrendo. A despedida reafirma os laços de ligação entre as pessoas, ajuda a fazer do morrer uma experiência compartilhada, auxilia na preparação psicológica e contribui para o término dos relacionamentos (Kellehear \& Lewin, 1988-89).

Pode-se cogitar, também, que o ritual de despedida proporciona melhores condições para enfrentar e elaborar o luto depois da morte, devido à oportunidade de redefinirem seus relacionamentos com o parente ainda em vida, aliviando sentimentos de cuipa e remorso. Imber-Black (1998) destaca a importância dos rituais de luto como facilitadores da elaboração após uma morte, proporcionando mudanças no relacionamento familiar e evitando o surgimento de sintomas. Ribeiro (1994) e Worden (1997) destacam que os momentos anteriores à morte podem ter um impacto muito importante no luto, se o familiar sobrevivente for estimulado a tratar assuntos pendentes, expressar agradecimentos e decepções, que devem ser ditas antes que a pessoa morra. $O$ fato da família permanecer ao lado do doente até o momento de sua mórte, expressando suas emoções e sentimentos, auxilia na elaboração da perda e na vivência do luto, pois pode proporcionar mudanças importantes nos padróes de relacionamento familiar. Bromberg (1994) afirma que o luto começa a ser determinado pela qualidade das relações e dos vínculos familiares anteriores à morte, e pelas condições que atuam nos momentos próximos à mesma, sendo que um dos fatores de risco para o desenvolvimento do luto patologi- 
co é a relação ambivalente ou de discórdia e discussões.

Portanto, se o profissional estimular os membros da família e os pacientes a se comunicarem e resolverem estas questões, o período pré-morte pode ter um efeito muito saudável em todos os envolvidos, pois o sobrevivente näo precisará tratar posteriormente de arrependimentos sobre coisas que nunca disse quando teve a oportunidade. Muitas vezes, o familiar necessita de estímulo ou permis. são para fazê-lo.

Uma questão significativa com relação ao ritual de despedida é o efeito de cura pessoal e redefinição dos vínculos familiares. Como muitas mortes, atualmente, ocorrem em hospitais, a orientação psicológica para o ritual de despedida pode ajudar os familiares no manejo da perda, atuando como um ritual de cura (Imber-Black, 1991,1995), pois assinala uma perda profunda, lida com a tristeza dos sobreviventes e parece facilitar a continuação da vida dos mesmos. Parece, então, que o ritual de despedida na iminência da morte pode atuar como um ritual curativo terapêutico.

O ritual de despedida também parece atuar na franqueza do sistema (Brown, 1995), ajudando também a pessoa a identificar e expressar seus sentimentos; e a dizer um adeus apropriado. Parece proporcionar, ainda, um resgate do relacionamento entre o familiar e o paciente, bem como os aproxima neste momento tão doloroso, abrindo a comunicação entre eles e aliviando o sentimento de impotência. $O$ ritual pode fazer, também, com que os familiares sintam estar fazendo algo pelo ente querido, num momento em que o sentimento de não ternada a fazer está tão presente.

O que parece diferenciar o ritual de despedida na iminência da morte dos chamados rituais de luto pós-morte, é o fato da pessoa que está morrendo também se beneficiar de seus efeitos, de acordo com as falas dos familiares entrevistados, que relataram terem observado que o paciente parecia mais tranquiilo e sereno, sentindo-se amado e àcompanhado pelos familiares nos seus momentos finais.

Constatou-se que a maioria dos familiares entrevistados ainda tinha pequenas questões pendentes com o familiar morto, relativas a alimentos que este desejava comer e não foi possível dar, gritos que o familiar deu com o paciente, devido, muitas vezes, ao stress do cuidador, receio de não ter cuidado do paciente o suficiente, de não ter estado mais perto antes do adoecimento, agradecimentos que gostaria de ter feito, e um túmulo digno para seu parente. Porém, apesar de ainda terem algumas "dívidas" com o morto, pareceu que em geral não havia ficado um grande remorso, pois as questões mais importantes pareciam estar resolvidas.

Bromberg (1998) constatou que os familiares tinham necessidade de se assegurar que tinham feito tudo o que era possível no sentido de oferecer conforto ao paciente, porém ficavam com uma sensação de terem falhado, de terem deixado passar algo que poderia tê-lo salvo. A mesma autora (1994), sobre a sintomatologia do luto, destaca o sentimento de culpa como um dos sintomas afetivos do luto, que inclui autoacusações sobre eventos do passado, principalmente aqueles que podem ter levado à morte, e comportamentos em relação ao morto. A Organização Mundial de Saúde (1998) coloca, como um dos sintomas do Transtorno de perda, a culpa e a auto-crítica. Isto reforça a importância do familiar ter uma oportunidade, ainda antes da morte de um parente, de aliviar estes sentimentos negativos que possam estar permeando a relação entre eles. Nos casos pesquisados, aparentemente as questões mais significativas foram resolvidas antes da morte, e o que ainda estava pendente poderia ser resolvido $a$ posteriori.

Notou-se que o tempo entre a despedida e a morte do paciente, em quase todos os casos pesquisados, foi de no máximo cinco dias, sendo que a maioria foi poucas horas após ou no dia seguinte. Isto pode nos levar a cogitar que realmente os pacientes com prognóstico reservado podem "esperar" por alguma resolução de questōes pendentes, por um "fechamento" de suas relações, e/ou por uma autorização para partir, para poderem morrer com mais tranqüillidade. Na literatura a que se teve acesso esta questão não foi abordada. Porém, diante dos relatos dos pacientes entrevistados nesta pesquisa, pode-se cogitar que o paciente "espera" por algo, pois as mortes, nestes casos, aconteceram próximas ao ritual de despedida.

Observou-se que a maioria dos familiares entrevistados ficou com boas lembranças do familiar 


\section{Márcia Lucrecia Lisbôa}

morto, lembrando-se deste com carinho. Pode-se observar nos relatos que, independentemente da qualidade anterior da relação, os familiares mantinham boas lembranças do parente falecido. Todos os familiares se referiram somente às qualidades do morto, o que, segundo Bromberg (1994), faz parte da sintomatologia do luto, pois, no início do processo do luto pós-morte, o familiar tem a necessidade de manter vivo o morto, através de lembranças e tentativas de contato. Um dos sintomas característicos do processo de luto é a idealização do falecido, quando o familiar ignora os defeitos e exagera as características positivas da pessoa que morreu. Isto pode ser constatado nas falas dos familiares pesquisados, mas pode-se cogitar também que as qualidades da pessoa falecida eram genuínas, e que o familiar estava apenas relatando a realidade ou, depois da relação redefinida, conseguia ver as qualidades que antes não era possível, devido aos sentimentos de raiva e mágoa. Também pode-se ter a hipótese de que o ritual de despedida auxiliou no sentido dos familiares poderem lembrar do seu ente querido com carinho.

Experiência anterior com os rituais de despedida no pré-óbito

A maioria dos familiares entrevistades não havia feito rituais de despedida antes da morte, em oportunidades anteriores. Os motivos alegados para não terem se despedido em outras ocasiões foi por terem sido mortes repentinas, não estavam junto à pessoa nos momentos próximos à morte, não tiveram coragem, ou não acompanharam a internação. Podese pensar, ainda, que naquela ocasião não foram estimulados e orientados por algum profissional para a realização do ritual. Os que tiveram esta experiência anteriormente descreveram questões semelhantes às colocadas nesta pesquiisa.

Brown (1995) escreve que um dos fatores que afetam o impacto da morte e da doença grave no sistema familiar, rompendo o equilíbrio, é a história de perdas anteriores. Pois mortes passadas e o fato de como a família lidou com elas influenciam no modo como a família lidará com a morte atual. Neste sentido, é importante checar com os familiares se eles já tiveram que enfrentar alguma morte na família, como foi esta experiência, e se despediram-se da pessoa antes de sua morte, comparando-se a vivência anterior com a atual e fazendo os "ajustes" necessários.

\section{Considerações finais}

O processo de despedida da família diante de um paciente que está morrendo é um momento solene, apesar da simplicidade com que o mesmo pode ocorrer. Requer um preparo emocional, uma disponibilidade, em algum nível, para aceitar a morte e o desapego. Uma das metas do trabalho com famílias que possuem um doente com prognostico reservado deve ser ajudá-los a ficarem próximos, enquanto preparam-se para a separação, e estimulá-los a se comunicarem com seus parentes que estão morrendo.

Quando há a necessidade de intervenção da parte de algum profissional qualificado, existem algumas questões que precisam ser avaliadas junto ao familiar como: quem são as pessoas que possuem um maior vínculo com o paciente, ou que possuem uma relação mais dependente dele; em que fase as pessoas mais significativas para o paciente se encontram, com relação à aceitação ou não da morte; qual a qualidade e os padrões das relações familiares; quem tem questões mal resolvidas com o paciente; 0 que os familiares gostariam de dizer ou fazer ao paciente, como agradecimentos, pedidos de perdão, entre outros, e como estão vivenciando o luto antecipatório.

$O$ trabalho com as famílias deve facilitar a proximidade com o paciente e ajudar a aliviar a "carga" de cuidar. Deve-se estar atento para os fatores que ajudam a aceitar a morte: a doença prolongada, o estar próximo e cuidar, a aceitação da morte pelo paciente, a boa morte, a idade do paciente e a experiência com perdas anteriores.

Muitas vezes, percebe-se que os familiares têm dificuldades em esperar o momento da morte devido à ansiedade diante do sofrimento, e querem apressála. Ou então, querem evitá-la, prolongando o seu momento. Neste sentido, deve-se estar atento à necessidade e à importância de se fazer alguma intervenção para tentar auxiliar a família, orientando-a a ter paciência e força para esperar um pouco mais pela morte efetiva do parente, ou para aceitá-la e "deixar o paciente partir". É fundamental estar atento para perceber qual (is) membro (s) da família está (ão) com dificuldades relativas a esta questão. 
O modo como o ritual de despedida pode ser feito é, geralmente, muito simples e ao mesmo tempo, abrangente. É importante respeitar a vontade, os limites e o modo pessoal de cada familiar, oferecendo todas as possibilidades, que incluem a comunicação verbal e não-verbal, o "estar junto" e a "liberação", ou seja, a mensagem de que respeitarão sua escolha de continuar lutando pela vida, ou aceitarão a possibilidade de morte.

As crenças e $o$ apoio da religião também aparecem com destaque, o que reforça a importância dos profissionais respeitarem o aspecto espiritual no acompanhamento destas famílias, respeitando suas crenças pós-morte e seus rituais religiosos.

O ritual de despedida parece beneficiar tanto o paciente quanto a família, mesmo se o primeiro estiver comatoso. Os efeitos de redefinição dos relacionamentos, de (re)afirmação dos sentimentos positivos, de ajuda no enfrentamento da morte e, possivelmente, do luto, o alívio de sentimentos "negativos", parecern ajudar na qualidade da morte do paciente $e$ na qualidade da vida dos familiares. Parece atuar, também, no sentimento de pertenência, pois pode aproximar ou resignificar relações anteriormente comprometidas, ou reafirmar relações já próximas.

Além da função de resgate dos relacionamentos, o ritual de despedida anterior à morte iminente pode ajudar as famílias na elaboração do luto, devido ao alívio da culpa e de outros sentimentos negativos. O ritual parece, ainda, ter os aspectos de solenidade, de sagrado e de homenagem, marcando o momento como sendo um momento especial.

O ritual de despedida pode ser visto como um resgate da morte domada (Ariès, 1977), onde a pessoa que está morrendo volta, de certa forma, a ser responsável pelos seus últimos momientos, permanecendo entre seus familiares e amigos, todos estando cientes da morte proxima. O ritual é feito de forma cerimonial, mas sem dramatização excessiva, sendo uma atitude familiar e próxima. A morte invertida parece se descaracterizar, pois o ritual faz com que a morte seja percebida, que se fale sobre ela, não mais a ignorando. A morte repentina passa a não ser mais considerada a boa morte, pois não oferece a oportunidade da despedida e da redefinição de relacionamentos e resolução de questões pendentes.

As opiniões unânimes, favoráveis ao ritual de despedida, bem como a importância atribuída à intervenção psicológica, são resultados significativos e gratificantes, pois mostram que são fundamentais no enfrentamento da iminência da perda de um ente querido. A oportunidade de poder se despedir do paciente com este ainda em vida, parece fazer diferença na aceitação da morte, podendo-se cogitar que facilita tarmbém a elaboração do luto pós-6́bito. Porém, outras pesquisas precisam ser feitas, para investigar mais amplamente e mais profundamente estas questões.

\section{Referências bibliográficas}

Andolfi, M. (1996). A terapia familiar: Um enfoque interacional. Campinas: Workshopsy.

Ariès, P. (1977). O homem diante da morte. Rio de Janeiro: Francisco Alves

Bardin, L. (1984). Análise de conteúdo. Lisboa: Edições 70

Barrêtto, F.J.T. (1992). A morte e o morrer: A assistência ao doente terminal. Em J. de Mello Filho (Org.), Psicossomática hoje (pp. 287-296). Porto Alegre: Artes Médicas

Bowen, M. (1998). A reação da família à morte. Em F. Walsh \& M. McGoldrick (Orgs.), Morte na família: Sobrevivendo às perdas (pp. 105-117). Porto Alegre: Artes Médicas.

Bromberg, M.H.P.F. (1994). Famílias enlutadas. Em M.M.M.J. de Carvalho (Org.), Introdução $\grave{a}$ psiconcologia (pp. 243-259). Campinas: Psy

Bromberg, M.H.P.F. (1997). A psicoterapia nas situações de perdas e luto. Campinas: Psy

Bromberg, M.H.P.F. (1998). Cuidados paliativos para o paciente com câncer: Uma proposta integrativa para equipe, pacientes e famílias. Em M.M.M.J. de Carvalho (Org.), Psico-oncologia no Brasil: Resgatando o viver (pp. 186-231). São Paulo: Summus

Brown, F.H. (1995). O impacto da morte e da doença grave sobre o ciclo de vida familiar. Em B. Carter \& M.McGoldrick (Orgs.), As mudanças no ciclo de vida familiar (pp. 393-412). Porto Alegre: Artes Médicas 
108 Márcia Lucrecia Lisbôa

Calil, V.L.L. (1987). Terapia familiar e de casal: Introdução às abordagens sistêmica $e$ psicanalítica. São Paulo: Summus

Crepaldi, M.A. (1989). Hospitalização infantil: Estudo das interações família-equipe hospitalar. Dissertação de Mestrado, Pontifícia Universidade Católica, Rio de Janeiro

Franklin, J. (1997). Apoio ao enlutado no cuidado paliativo. Em C. M. Nascimento-Schulze (Org.), Dimensões da dor no câncer (pp. 117-132). São Paulo: Robe

Friedman, E.H. (1995). Sistemas e cerimônias: Uma visão familiar dos ritos de passagem. Em M. McGoldrick \& B. Carter (Orgs.), As mudanças no ciclo de vida familiar (pp. 106-130). Porto Alegre: Artes Médicas

Groisman, M. (1991). Familia, trama e terapia: A responsabilidade repartida. Rio de Janeiro: Objetiva

Imber-Black, E. (1991). Motivos rituales en las familias y en la terapia familiar. Em E. ImberBlack, J. Roberts \& R. Whiting (Orgs.), Rituales terapeuticos y ritos en la familia. (pp. 25-71). Barcelona: Gedisa

Imber-Black, E. (1995). Transições idiossincráticas de ciclo de vida e rituais terapêuticos. Em M. McGoldrick \& B. Carter (Orgs.), As mudanças no ciclo de vida familiar (pp. 131-143). Porto Alegre: Artes Médicas

Imber-Black, E. (1998). Os rituais e o processo de elaboração. Em F. Walsh \& M. McGoldrick (Orgs.), Morte na familia: Sobrevivendo às perdas (pp. 229-245). Porto Alegre: Artes Médicas

Jann, I. (1998). Enfrentando o morrer: A experiência de luto (a) do paciente com câncer avançado e de seus familiares. Dissertação de Mestrado, Pontifícia Universidade Católica, São Paulo

Jann, I. (1999). O luto antecipatório: Histórico, conceitos e controvérsias. Psicologia Argumento, $17(25), 69-80$
Kellehear, A. \& Lewin, T. (1988-89). Farewells by the dying: A sociological study. Omega. 19 (4), 275-292

Kovács, M. J. (1991). Pensando a morte e a formação de profissionais de saúde. Em R.M.S. Cassorla (Org.), Da morte: Estudos brasileiros. (pp. 79-103). Campinas: Papirus

Kübler-Ross, E. (1996). Morte, estágio final da evolução. Rio de Janeiro: Nova Era

Lebow, G.H. (1976). Facilitating adaptation in antecipatory mourning. Social Caseworks. 57, $458-465$

Moore, S.F. \& Myerhoff, B.G. (1977). Secular ritual. Amsterdam: Van Gorcum

Organização Mundial de Saúde (1998). CID-10 Diretrizes diagnósticas $e$ de tratamento para transtornos mentais em cuidados primários. ( $1^{\mathrm{a}}$ ed. revisada). Porto Alegre: Artes Médicas

Reeves, N.C. \& Boersma, F.J. (1990). The therapeutic use of ritual in maladaptive grieving. Omeg,. 20 (4), 281-29

Ribeiro, E.M.P.C. (1994). O paciente terminal e a família. Em M.M.M.J. de Carvalho (Org.), Introdução à psiconcologia (pp.197-217). Campinas: Psy

Rolland, J.S. (1995). Doença crônica e o ciclo de vida familiar. Em: B. Carter \& M. McGoldrick (Orgs.), As mudanças no ciclo de vida familiar (pp. 393412). Porto Alegre: Artes Médicas

Rolland, J.S. (1998). Ajudando famílias com perdas antecipadas. Em F. Walsh \& M. McGoldrick (Orgs.), Morte na família: Sobrevivendo às perdas (pp. 166 a 186). Porto Alegre: Artes Médicas

Scheff. T.J. (1979). Catharsis in healing ritual and drama. Berkeley, Los Angeles: University of California Press

Simonton, S.M. (1990). A família e a cura. São Paulo: Summus 
Torres, W.C. (2001). As perdas do paciente terminal:

. O luto antecipatório. Psicologia Argumento, 19 (28), 7-12

Walsh, F. \& McGoldrick, M. (1998). A perda e a família: uma perspectiva sistêmica. Em F. Walsh \& M. McGoldrick (Orgs.), Morte na família: Sobrevivendo às perdas (pp. 27-55). Porto Alegre: Artes Médicas

Whitaker, C.A. \& Bumberry, W.M. (1990). Dançando com a família: Uma abordagem simbólico-experencial. (R.E. Starosta, Trad.). Porto Alegre: Artes Médicas.

Worden, J.W. (1997). El tratamiento del duelo: Asesoramiento psicológico y terapia. Buenos Aires: Paidós.

Trabalho derivado de Dissertação de Mestrado Programa de Pós Graduação em Psicologia do Centro de Filosofia e Ciências Humanas da Universidade Federal de Santa Catarina. 